ELKOMIIKA: Jurnal Teknik Energi Elektrik, Teknik Telekomunikasi, \& Teknik Elektronika.

\title{
Pengoptimalan Kinerja Pengereman Regeneratif Motor BLDC menggunakan Cascaded Boost Converter
}

\author{
DANIEL RAHADIAN FIRMANTO, SLAMET RIYADI, LEONARDUS HERU \\ PRATOMO, FLORENTINUS BUDI SETIAWAN
}

\author{
Teknik Elektro Universitas Katolik Soegijapranata Semarang, Indonesia \\ Email: dnlrahadian@gmail.com
}

Received 6 Desember 2020| Revised 16 Januari 2021| Accepted 5 Februari 2021

\begin{abstract}
ABSTRAK
Mesin Brushless Dircet Current (BLDC) digunakan pada kendaraan listrik karena memiliki torsi yang besar dan memungkinkan untuk pengereman regeneratif. Pengereman regeneratif dirancang agar kendaraan listrik memiliki jarak tempuh yang lebih panjang. Pada saat pengereman, konverter bidirectional dioperasikan menjadi boost rectifier agar energi dapat berpindah ke baterai. Boost rectifier memiliki gain yang rendah, sehingga pengiriman daya ke baterai kurang optimal. Pada penelitian ini ditambahkan chopper kedua yang memiliki gain tinggi agar pengiriman daya lebih optimal. Metode modulasi lebar pulsa yang dibangkitkan mikrokontrol dsPIC30f4012 digunakan untuk mengendalikan saklar (IRFP 460) pada konverter. Verifikasi menggunakan perangkat keras telah dilakukan untuk mendukung penelitian ini. Hasil percobaan pada duty cycle 0,8 dapat dihasilkan arus pada baterai sebesar 0,25 A dan kecepatan berkurang menjadi 663 rpm.
\end{abstract}

Kata kunci: BLDC, Pengereman regeneratif, Boost rectifier, chopper, dsPIC30f4012

\begin{abstract}
Brushless direct current (BLDC) machine is suitable to be implemented in electric vehicle since it can provide high torque and is capable to do regenerative braking. For electric vehicle applications, the regenerative braking is needed to make such vehicle can travel longer distance. For making the machine current can flow into the battery, the bidirectional converter will be operated as a boost rectifier: The boost rectifier produced a low gain so that the second chopper with a high gain is required. The pulse width modulation (PWM) method was used to control each switch (IRFP 460) using a dsPIC30F4012 microcontroller- $A$ verification with experimental work was done. Based on the result, with 0.8 duty cycle can produced a 0.2 A battery current also and speed reduced to $663 \mathrm{rpm}$.
\end{abstract}

Keywords: BLDC, Regenerative braking, Boost rectifier, chopper, dsPIC30f4012 
Pengoptimalan Kinerja Pengereman Regeneratif Motor BLDC menggunakan Cascaded Boost Converter

\section{PENDAHULUAN}

Dewasa ini kendaraan dengan mesin baker mulai tergantikan dengan kendaraan listrik yang ramah lingkungan (Kumar, dkk, 2018). Mesin BLDC sering digunakan untuk kendaraan listrik karena memiliki torka yang besar, efisiensi tinggi dan memungkinkan untuk pengereman regeneratif (Mohammad \& Khan, 2015) (Riyadi \& Dwi Setianto, 2019). Pengereman regeneratif dapat membuat kendaraan memiliki jarak tempuh yang lebih panjang (Chougale \& Lakade, 2018). Jarak tempuh dapat meningkat $16,23 \%$ lebih panjang setelah menerapkan pengereman ini pada kendaraan listrik (Bhurse \& Bhole, 2018). Pengereman regeneratif memanfaatkan energi kinetik pada mesin yang diubah menjadi energi listrik untuk pengisian daya ke baterai (Bobba \& Rajagopal, 2010). Tegangan mesin selalu lebih rendah dari tegangan baterai, maka harus dilakukan proses penguatan agar terjadi pengiriman daya ke baterai (Milivojevic, dkk, 2010).

Bidirectional converter dioperasikan menjadi boost rectifier agar tegangan keluaran mesin lebih tinggi dari tegangan baterai. Boost rectifier menggunakan saklar bagian bawah sebagai switching dan saklar bagian atas sebagai dioda pada konverter bidirectional (Aswathi, dkk, 2018). Jika pensaklaran dilakukan ketika Back Electromotive Force (BEMF) pada kondisi puncak maka terjadi pengiriman daya secara maksimal. Puncak BEMF dapat diketahui dari sensor hall-effect yang terdapat pada mesin BLDC (Nugroho \& Riyadi, 2019) (Riyadi \& Dwi Setianto, 2019).

Boost rectifier mengadopsi prinsip kerja dari boost converter, di mana belitan stator pada mesin BLDC sebagai induktornya. Saat saklar dalam kondisi-on, belitan stator akan menyimpan energi dalam bentuk medan magnet. Pada saat saklar dalam kondisi-off, belitan stator mengubah polaritasnya untuk mengirimkan daya ke baterai. Boost converter memiliki efisiensi mencapai 85,32\% (Boujelben, dkk, 2017) (Maradzhiev, dkk, 2018). Tujuan dari penelitian ini adalah memberikan solusi agar arus yang masuk ke baterai semakin besar sehingga kendaraan listrik memiliki jarak tempuh yang lebih panjang.

\section{METODOLOGI}

\subsection{Generator BLDC}

Energi kinetik pada rotor akan mengakibatkan perubahan fluksi pada belitan stator. Prinsip generator ini berdasarkan Hukum Faraday dengan persamaan disajikan dalam Persamaan (1).

$$
e=N \frac{d}{d t} \Phi
$$

Di mana $e, N$ dan $\Phi$ adalah $\mathrm{GGL}$, jumlah lilitan pada stator dan fluksi. GGL keluaran dari generator BLDC dikuatkan menggunakan boost rectifier dan chopper kedua. Blok diagram generator BLDC disajikan pada Gambar 1. 


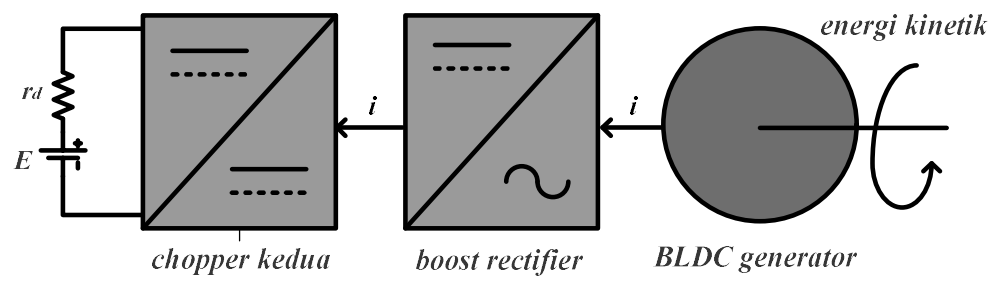

Gambar 1. Blok Diagram Generator BLDC (Riyadi, dkk, 2019)

Batasan dari boost rectifier adalah gain yang rendah, sehingga diperlukan penguatan menggunakan chopper kedua agar mendapatkan gain yang lebih tinggi (Maitra \& Debnath, 2018) (Moutabir, dkk, 2014). Rangkaian ekuivalen generator BLDC berdasarkan Gambar 1 disajikan pada Gambar 3.

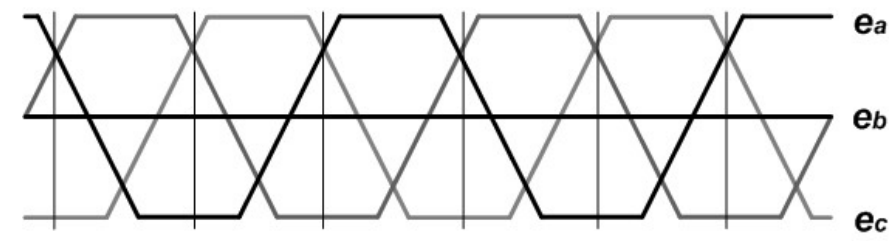

Gambar 2. Tegangan Keluaran Generator BLDC (Riyadi, dkk, 2019)

Mesin BLDC yang diputar oleh energi kinetik akan menghasilkan Gaya Gerak Listrik (GGL) berbentuk trapezoidal yang disajikan pada Gambar 2 (Lee \& Ehsani, 2004) (Laczko, dkk, 2015).

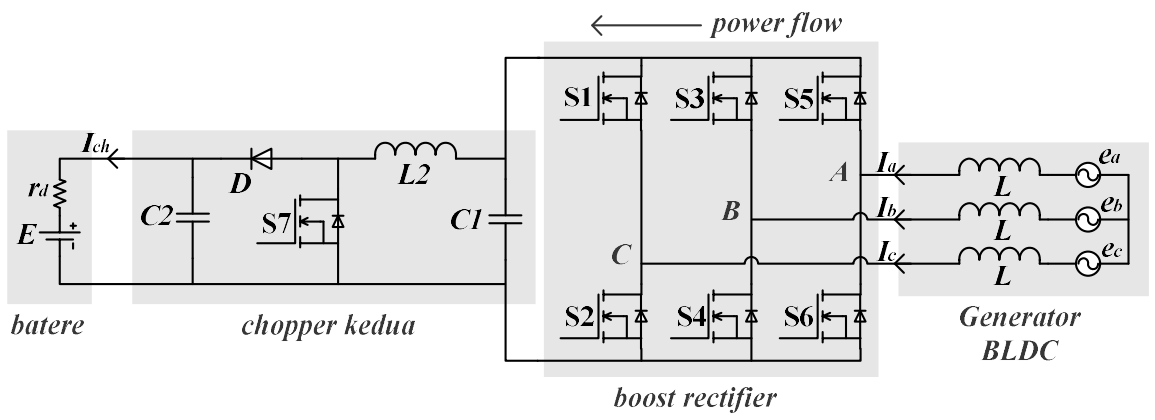

Gambar 3. Rangkaian Ekuivalen Generator BLDC (Riyadi, dkk, 2019)

\subsection{Cascaded Boost Converter}

Cascaded boost converter memiliki dua kemungkinan metode penyaklaran yang berlaku, yaitu simultant dan geser fasa $90^{\circ}$ (Tofoli, dkk, 2015) (Malik, dkk, 2017). Cascaded boost converter dengan metode penyaklaran simultan memiliki dua mode operasi yaitu pada saat kedua saklar dalam kondisi-on dan kondisi-off. Pada saat saklar dalam kondisi-on, belitan akan menyimpan energi dalam bentuk medan magnet. Cascaded boost converter memiliki efisiensi mencapai 94,54\% (Boujelben, dkk, 2017). Rangkaian ekuivalen pengereman regeneratif mesin BLDC saat belitan menyimpan energi disajikan pada Gambar 4 dan rangkaian ekuivalen cascaded boost converter ketika saklar dalam kondisi-on disajikan pada Gambar 5. 


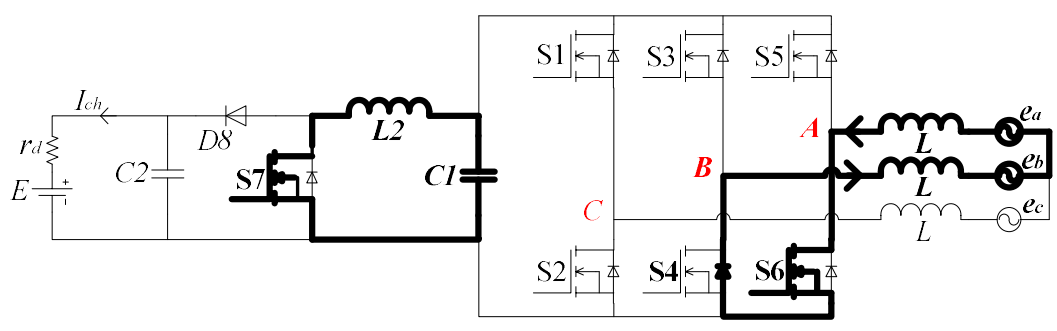

Gambar 4. Rangkaian Ekuivalen Pengereman Regeneratif Mesin BLDC pada Saat Belitan Menyimpan Energi (Riyadi, dkk, 2019)

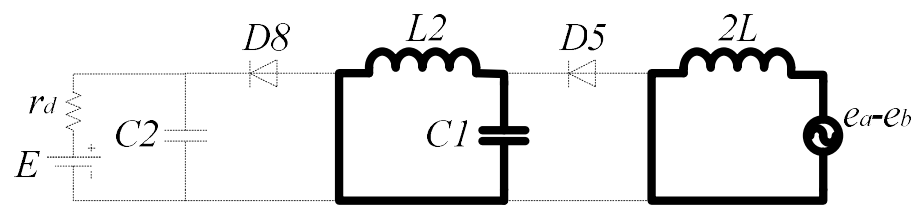

Gambar 5. Rangkaian Ekuivalen Cascaded Boost Converter ketika Saklar dalam Kondision (Riyadi, dkk, 2019)

Berdasarkan rangkaian pada Gambar 5 , persamaan tegangan dan arus sesaat pada $2 L$ dinyatakan dengan Persamaan (2).

$$
\Delta i_{a}=\frac{e_{a}-e_{b}}{2 L} t_{\text {on }}
$$

Persamaan tegangan dan arus sesat pada $L 2$ dinyatakan dengan Persamaan (3).

$$
\Delta i_{a}=\frac{V_{C 1}}{L 2} t_{\text {on }}
$$

Di mana $e_{a}, e_{b}, v_{L}, i_{a}, \Delta i_{a}$ adalah BEMF dari fasa-A, BEMF dari fasa-B, tegangan pada induktor, dan fluktuasi dari arus fasa-A. Setelah induktor menyimpan energi dalam bentuk medan magnet, saklar dalam kondisi-off akan membuat energi pada induktor mengalir melalui dioda (Boujelben, dkk, 2019). Rangkaian ekuivalen pengereman regeneratif mesin BLDC saat energi pada belitan mengalir melalui dioda disajikan pada Gambar 6 dan rangkaian ekuivalen cascaded boost converter ketika saklar dalam kondisi-off disajikan pada Gambar 7.

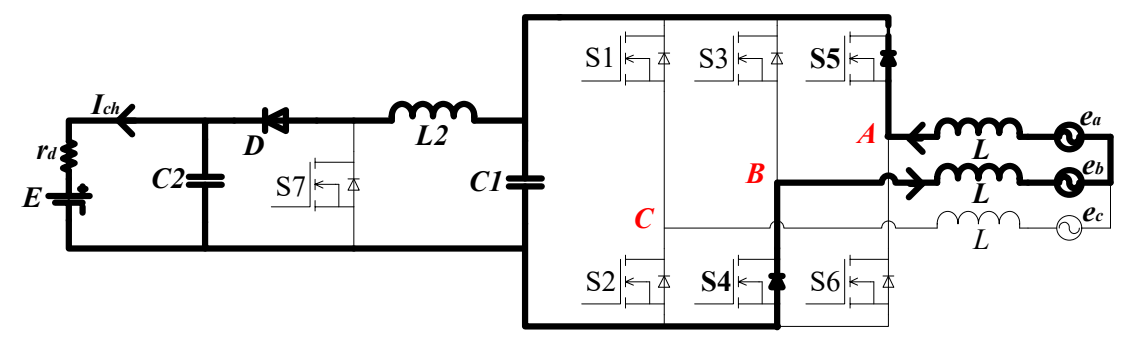

Gambar 6. Rangkaian Ekuivalen Pengereman Regeneratif Mesin BLDC saat Energi pada Belitan Mengalir Melalui Dioda (Riyadi, dkk, 2019) 


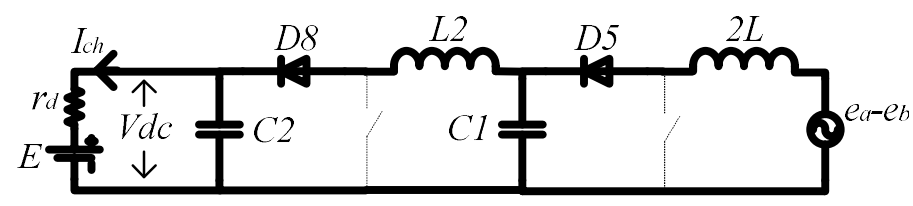

Gambar 7. Rangkaian Ekuivalen Cascaded Boost Converter saat Saklar dalam Kondisi-off (Riyadi, dkk, 2019)

Berdasarkan rangkaian pada Gambar 7, persamaan tegangan dan arus dinyatakan dalam Persamaan (4) dan Persamaan (5).

$$
\begin{gathered}
\Delta i_{a}=\frac{V_{C 1}-\left(e_{a}-e_{b}\right)}{2 L} t_{\text {off }} \\
\Delta i_{a}=\frac{V_{d c}-V_{C 1}}{L 2} t_{\text {off }}
\end{gathered}
$$

Berdasarkan Persamaan (4) dan Persamaan (5), tegangan keluaran cascaded boost converter dinyatakan dalam Persamaan (6).

$$
\frac{V_{d c}}{\left(e_{a}-e_{b}\right)}=\frac{1}{\left(1-d_{1}\right)} \frac{1}{\left(1-d_{2}\right)}
$$

Jika $r_{d}$ dan $E$ adalah hambatan dalam dan tegangan pada baterai, maka arus yang masuk ke baterai $\left(I_{c h}\right)$ dinyatakan dengan Persamaan (7).

$$
I_{c h}=\frac{V_{d c}-E}{r_{d}}
$$

\section{HASIL DAN PEMBAHASAN}

Berdasarkan metodologi penelitian maka dilakukan implementasi pada prototype dengan parameter mesin BLDC ditampilkan dalam Tabel 1 dan parameter konverter ditampilkan dalam Tabel 2.

\section{Tabel 1. Spesifikasi Mesin BLDC}

\begin{tabular}{|c|l|c|}
\hline No. & \multicolumn{1}{|c|}{ Parameter } & Nilai \\
\hline 1. & Number of poles & 4 \\
2. & Number of phases & 3 \\
3. & Rated voltage & $24 \mathrm{~V}$ \\
\hline
\end{tabular}


Tabel 2. Parameter Konverter

\begin{tabular}{|c|l|c|}
\hline No. & \multicolumn{1}{|c|}{ Parameter } & Nilai \\
\hline 1. & Saklar & IRFP460 \\
2. & Dioda & MUR860 \\
3. & Induktor 1 dan 2 & $8 \mathrm{mH}$ \\
4. & Kapasitor 1 & $1000 \mathrm{uF}$ \\
5. & Kapasitor 2 & $330 \mathrm{uF}$ \\
6. & Baterai & $12 \mathrm{~V} 10 \mathrm{Ah}$ \\
\hline
\end{tabular}

Tabel 1 dan 2 merupakan parameter pengujian perangkat keras. Implementasi perangkat keras dilakukan guna membuktikan bahwa sistem yang diusulkan dapat bekerja dengan baik. Implementasi menggunakan mesin BLDC yang diputar dengan motor DC untuk menyimulasikan energi kinetik pada saat pengereman. Penerapan perangkat keras dapat dilihat pada Gambar 8.

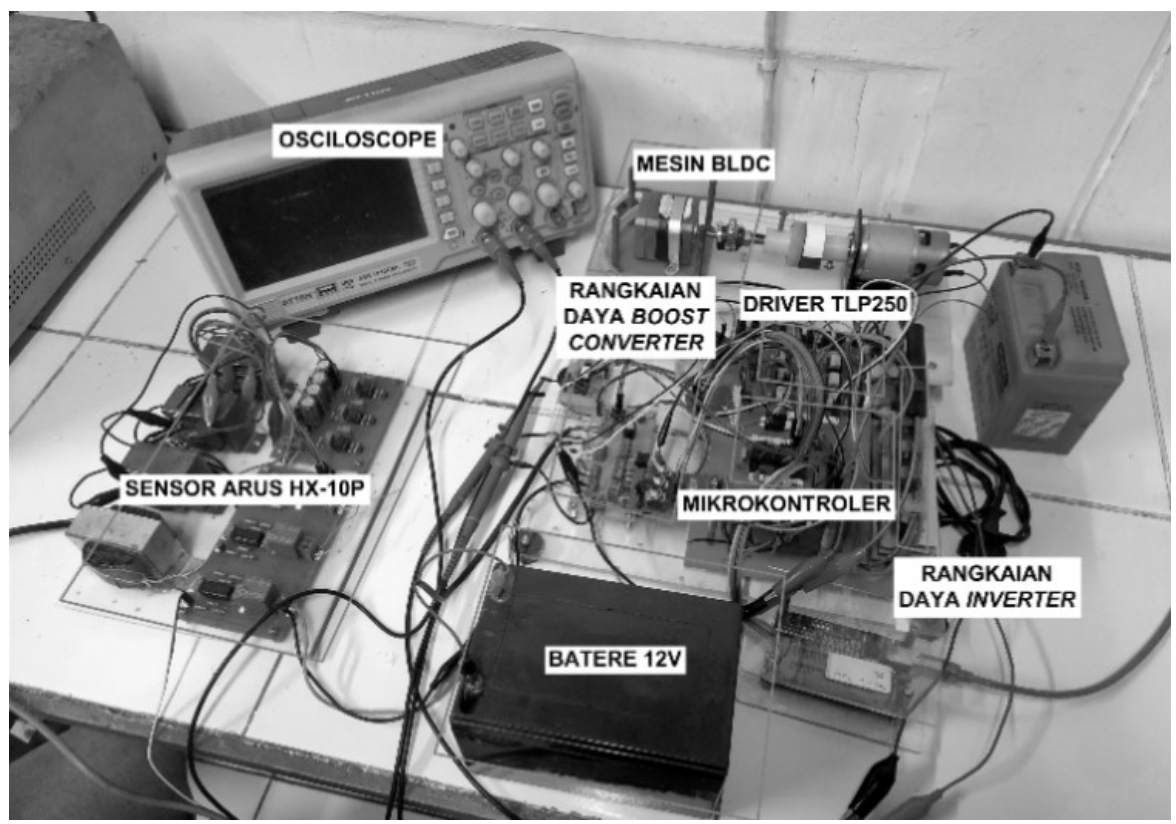

Gambar 8. Implementasi Perangkat Keras Pengereman Regeneratif Mesin BLDC menggunakan Cascaded Boost Converter

Pembuatan prototype berdasarkan rangkaian pada Gambar 3. Mesin BLDC $50 \mathrm{~W}$ dan baterai $12 \mathrm{~V}$ digunakan dalam prototype ini. Pada Gambar 9 ditampilkan BEMF fasa a, b, dan c pada saat rotor dari mesin BLDC diputar oleh energi kinetik sebelum terintegrasi dengan cascaded boost converter. 


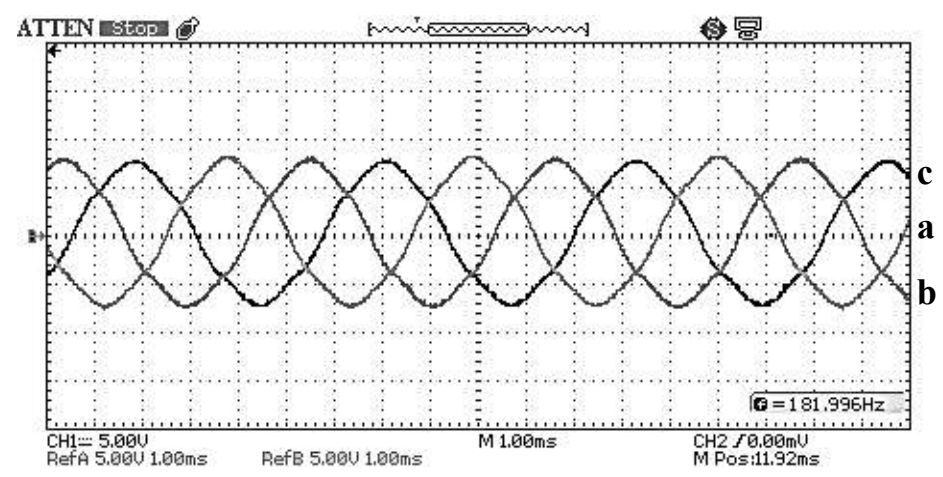

Gambar 9. Hasil Percobaan BEMF Fasa A, B dan C dari Mesin BLDC

Pada Gambar 10 disajikan BEMF fasa a, b, dan c dari mesin BLDC setelah terintegrasi dengan cascaded boost converter dengan duty cycle 0,3. BEMF terdistorsi akibat switching saklar pada konverter.

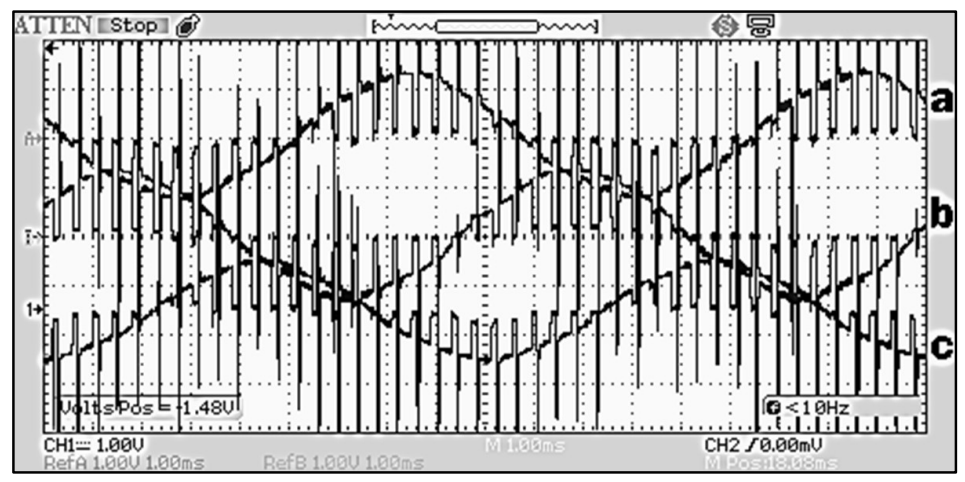

\section{Gambar 10. Hasil Percobaan BEMF Fasa A, B dan C dari Mesin BLDC Setelah Terintegrasi dengan Cascaded Boost Converter Dengan Duty Cycle 0,3}

Pada Gambar 11 disajikan arus pada induktor 2 (iL2) dengan duty cycle sebesar 0,3. Arus baterai sebesar 0,075 A berlaku discontinuous pada kondisi ini.

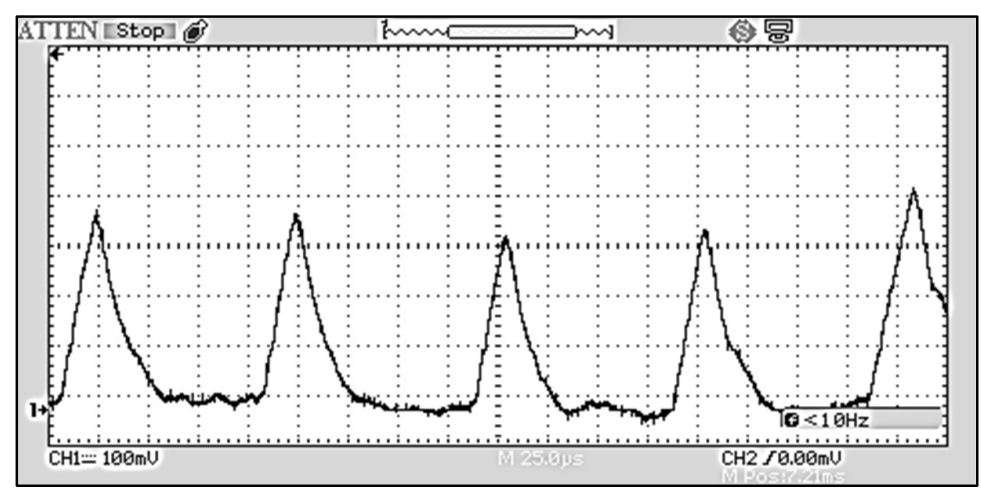

Gambar 11. Hasil Percobaan Arus pada Induktor (il2) Saat Duty Cycle 0,3 
Pada Gambar 12 disajikan arus pada induktor 2 (iL2) dengan duty cycle sebesar 0,5. Arus baterai sebesar 0,15 A dan berlaku discontinuous pada kondisi ini.

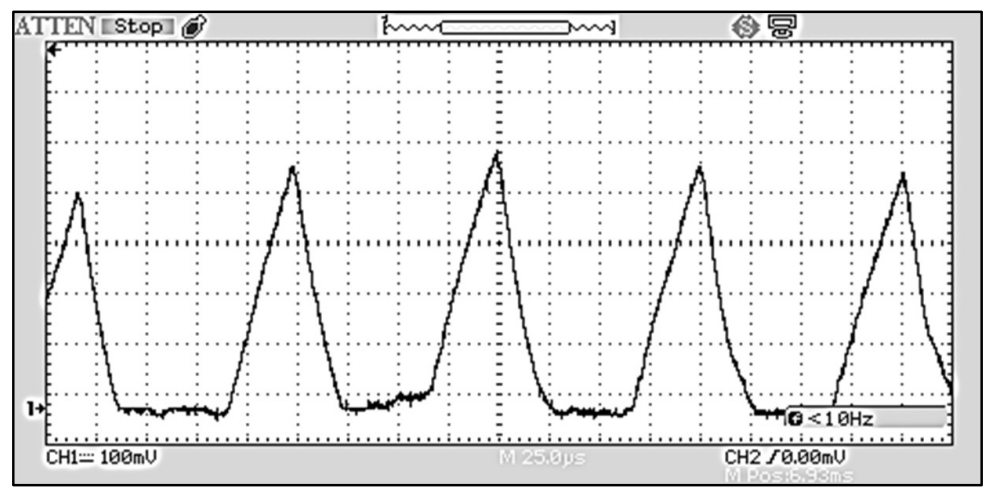

\section{Gambar 12. Hasil Percobaan Arus pada Induktor (il2) Saat Duty Cycle 0,5}

Pada Gambar 13 disajikan arus pada induktor 2 (iL2) dengan duty cycle sebesar 0,8. Arus baterai sebesar 0,25 A dan berlaku continuous pada kondisi ini.

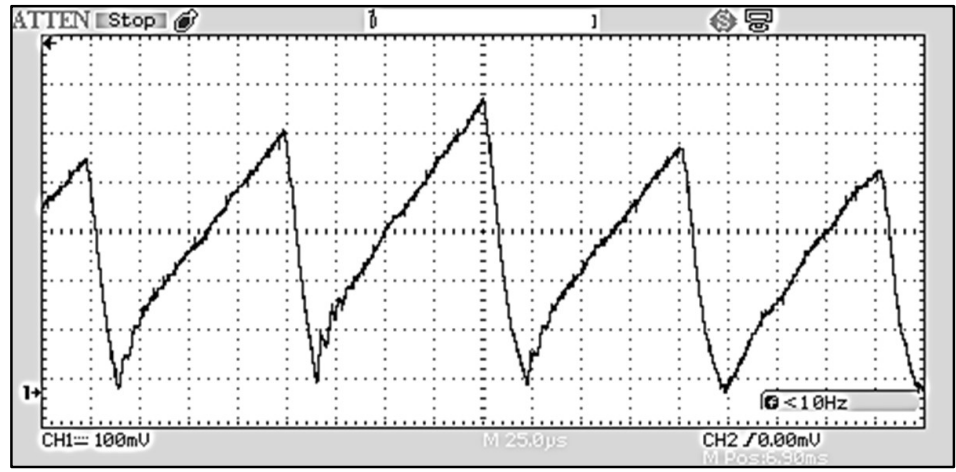

\section{Gambar 13. Hasil Percobaan Arus pada Induktor (il2) Saat Duty Cycle 0,8}

Pada Gambar 14 disajikan hasil percobaan arus keluaran konverter yang masuk ke baterai $\left(I_{c h}\right)$ dengan perubahan duty cycle. Semakin besar duty cycle maka arus yang masuk ke baterai semakin tinggi.

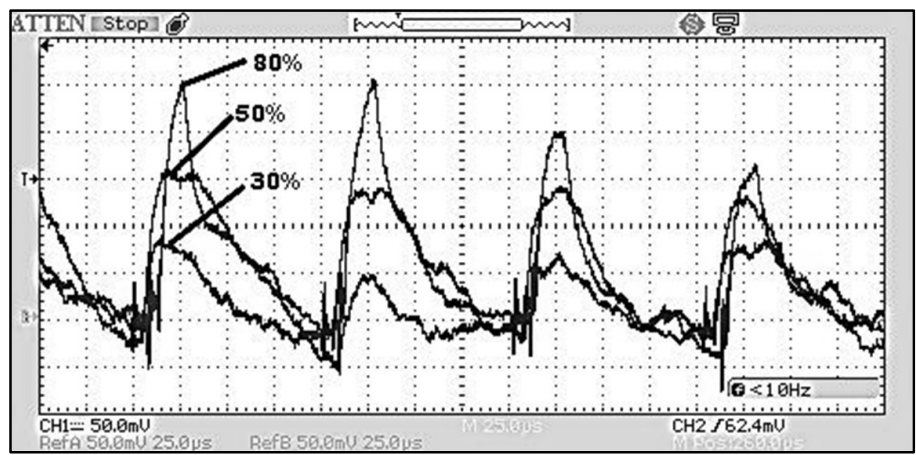

Gambar 14. Hasil Percobaan Perbandingan Arus yang Masuk ke Baterai $\left(I_{c h}\right)$ Saat Duty Cycle (A) 0,3 (B) 0,5 (C) 0,8 
Perubahan duty cycle juga berpengaruh pada kecepatan mesin BLDC. Semakin tinggi duty cycle maka kecepatan mesin BLDC akan semakin berkurang dengan hasil percobaan pada Gambar 15.

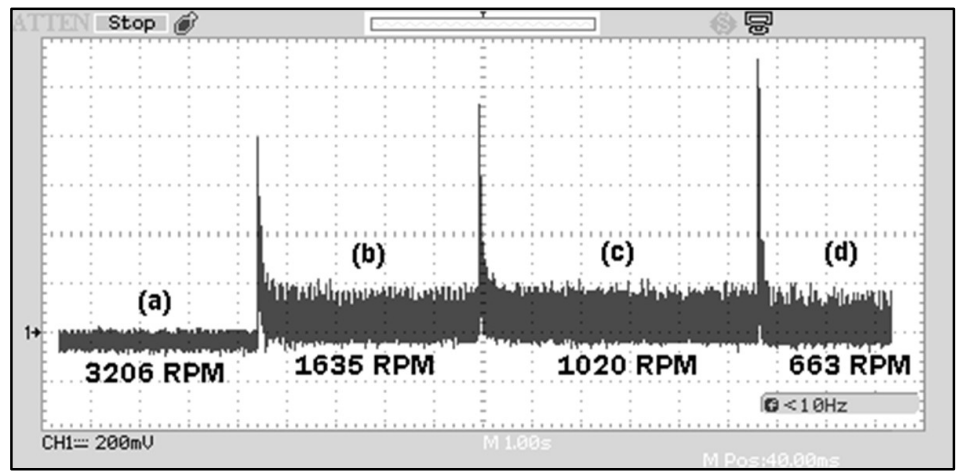

Gambar 15. Hasil Percobaan Intensitas Arus yang Masuk ke Baterai $\left(I_{c h}\right)$ dan Pengurangan Kecepatan Akibat Perubahan Duty Cycle (A) 0 (B) 0,3 (C) 0,5 (D) 0,8

Percobaan pengereman regeneratif mesin BLDC dilakukan dengan kecepatan saat duty cycle 0 atau kecepatan mula-mula yaitu $3206 \mathrm{rpm}$.

Tabel 3. Hasil Percobaan Pengurangan Kecepatan akibat Perubahan Duty Cycle

\begin{tabular}{|c|c|c|}
\hline No. & Duty Cycle & Kecepatan (rpm) \\
\hline 1. & 0 & 3206 \\
2. & 0,3 & 1635 \\
3. & 0,5 & 1020 \\
4. & 0,8 & 663 \\
\hline
\end{tabular}

Pada Tabel 3 ditampilkan hasil percobaan pengurangan kecepatan akibat perubahan duty cycle pada cascaded boost converter. Pada duty cycle 0,3 kecepatan mesin berkurang menjadi 1635 rpm. Pada duty cycle 0,5 kecepatan mesin berkurang menjadi 1020 rpm. Pada duty cycle 0,8 kecepatan mesin berkurang menjadi $663 \mathrm{rpm}$.

\section{KESIMPULAN}

Berdasarkan hasil percobaan, penambahan chopper kedua dapat memperbaiki gain saat pengereman regeneratif. Semakin besar duty cycle maka arus charging $\left(I_{c h}\right)$ ke baterai akan semakin tinggi. Perubahan duty cycle juga berpengaruh pada pengurangan kecepatan mesin BLDC, yaitu semakin tinggi duty cycle pada konverter maka kecepatan akan semakin berkurang. Pada duty cycle 0,8 dapat menghasilkan arus pada baterai sebesar 0,25 A dengan kecepatan berkurang menjadi $663 \mathrm{rpm}$.

\section{UCAPAN TERIMA KASIH}

Makalah ini merupakan bagian Penelitian yang didukung oleh Direktorat Riset dan Pengabdian Masyarakat, Dirjen Penguatan Riset dan Pengembangan, Kementrian Riset, Teknologi dan Pendidikan Tinggi dengan skema PTUPT 2020. 
Pengoptimalan Kinerja Pengereman Regeneratif Motor BLDC menggunakan Cascaded Boost Converter

\section{DAFTAR RUJUKAN}

Aswathi, E. R., Prathibha, P. K., \& Nair, J. R. (2018). Regenerative Braking of BLDC Motor using Fuzzy Control for Electric Vehicles. Proceedings of the International Conference on Inventive Communication and Computational Technologies, ICICCT 2018, (pp. 1661-1665). doi: 10.1109/ICICCT.2018.8473242

Bhurse, S. S., \& Bhole, A. A. (2018). A Review of Regenerative Braking in Electric Vehicles. 7th IEEE International Conference on Computation of Power, Energy, Information and Communication, ICCPEIC 2018, (pp. 363-367). doi: 10.1109/ICCPEIC.2018.8525157

Bobba, P. B., \& Rajagopal, K. R. (2010). Compact regenerative braking scheme for a PM BLDC motor driven electric two-wheeler. 2010 Joint International Conference on Power Electronics, Drives and Energy Systems, PEDES 2010 and 2010 Power India, (pp. 15). doi: 10.1109/PEDES.2010.5712566

Boujelben, N., Masmoudi, F., Djemel, M., \& Derbel, N. (2017). Design and comparison of quadratic boost and double cascade boost converters with boost converter. 2017 14th International Multi-Conference on Systems, Signals and Devices, SSD 2017, (pp. 245252). doi: 10.1109/SSD.2017.8167022

Boujelben, N., Masmoudi, F., Djemel, M., \& Derbel, N. (2019). Modeling and comparison of boost converter with cascaded boost converters. Green Energy and Technology, 85103. doi: 10.1007/978-981-13-1945-7_4

Chougale, R. G., \& Lakade, C. R. (2018). Regenerative braking system of electric vehicle driven by brushless DC motor using fuzzy logic. IEEE International Conference on Power, Control, Signals and Instrumentation Engineering, ICPCSI 2017, (pp. 2167-2171). doi: 10.1109/ICPCSI.2017.8392101

Kumar, B. V. R., Sivakumar, K., \& Karunanidhi, S. (2018). A novel configuration of regenerative braking system to improve the energy efficiency of an electric vehicle with Dual-Stator Dual-Rotor BLDC motor. 2017 IEEE Transportation Electrification Conference, ITECIndia 2017, (pp. 1-4). doi: 10.1109/ITEC-India.2017.8333858

Laczko, A. A., Zaharia, M. V., Radulescu, M. M., \& Brisset, S. (2015). Modeling and simulation of a brushless DC wind energy conversion system. 2015 Tenth International Conference on Ecological Vehicles and Renewable Energies (EVER) Modeling.

Lee, H. W., \& Ehsani, M. (2004). Practical control for improving power density and efficiency of the BLDC generator. Conference Proceedings - IEEE Applied Power Electronics Conference and Exposition - APEC, (pp. 1124-1129). doi: 10.1109/apec.2004.1295963

Maitra, A., \& Debnath, D. (2018). A Transformerless Doubly Boost DC-DC Converter for grid 
connetced solar photovoltaic systems. India International Conference on Power Electronics, IICPE, 2018-Decem, (pp. 1-6). doi: 10.1109/IICPE.2018.8709341

Malik, M. Z., Ali, A., \& Kumar, D. (2017). A Two Cascaded Boost Converter with High Voltage Gain Module. International Journal of Computer and Electrical Engineering, 9(2), 476483. doi: 10.17706/ijcee.2017.9.2.476-483

Maradzhiev, I. P., Grigorova, T. G., \& Dinkov, E. I. (2018). Analysis and Investigation of Methods for Energy Recovering from BLDC Motor. 9th National Conference with International Participation, ELECTRONICA 2018 - Proceedings, (pp. 1-4). doi: 10.1109/ELECTRONICA.2018.8439296

Milivojevic, N., Stamenkovic, I., Krishnamurthy, M., \& Emadi, A. (2010). A digital control strategy for brushless DC generators. Conference Proceedings - IEEE Applied Power Electronics Conference and Exposition - APEC, (pp. 1957-1962). doi: 10.1109/APEC.2010.5433502

Mohammad, A., \& Khan, M. Z. R. (2015). BLDC motor controller for Regenerative Braking. 2nd International Conference on Electrical Engineering and Information and Communication Technology, iCEEICT 2015, (pp. 21-23). doi: 10.1109/ICEEICT.2015.7307453

Moutabir, A., Abouloifa, A., Abdelmounim, E., Aboulfatah, M., Majdoul, R., \& Touati, A. (2014). Analysis and control design of two cascaded boost converter. MATEC Web of Conferences, (pp. 4-9). doi: 10.1051/matecconf/20141606004

Nugroho, I. W. A., \& Riyadi, S. (2019). Regenerative Braking with Duty Cycle Settings for Brushless DC Motor. Proceedings of the International Conference on Electrical Engineering and Informatics, 2019-July(July), (pp. 336-341). doi: 10.1109/ICEEI47359.2019.8988894

Riyadi, S., \& Dwi Setianto, Y. B. (2019). Analysis and Design of BLDC Motor Control in Regenerative Braking. Proceedings - 2019 International Symposium on Electrical and Electronics Engineering, ISEE 2019, (pp. 211-215). doi: 10.1109/ISEE2.2019.8920962

Tofoli, F. L., Pereira, D. de C., de Paula, W. J., \& Oliveira Júnior, D. de S. (2015). Survey on non-isolated high-voltage step-up dc-dc topologies based on the boost converter. IET Power Electronics, 8(10), (pp. 2044-2057). doi: 10.1049/iet-pel.2014.0605 